\title{
The Role of Scientific Research in the Policy-Making Process in African Economies
}

\author{
Wilfred Awung Ndongko ${ }^{1}$ Ismaila Amadu ${ }^{2 *}$ \\ 1.Cameroon Academy of Sciences, Cameroon \\ 2.National Committee for the Development of Technologies, Ministry of Scientific Research and Innovation, \\ Cameroon
}

\begin{abstract}
The central argument of this paper is that it is the responsibility of university and research institutions to undertake objective scientific research which can serve as the basis of formulating sound and sustainable socio-economic development policies in African countries. Unfortunately, scientific research as a tool of government policy has not been given adequate attention by policy-makers in many African Countries. In fact, the relationship between policy-makers and university / research and training institutions in the continent has not been very encouraging, particularly in those countries which have not established formal national structures for interface and dialogue. Thus, for scientific research findings to have the desirable impact on the policy-making process and the socioeconomic development in Africa, it is recommended among other things that: first, African governments should provide adequate funding and infrastructure for research; second, African universities and research institutions should aim at excellence by improving upon the quality of their scientific research, and properly address their research endeavours to the contemporary issues, challenges, and problems of national development; third, an interface to promote collaboration and cooperation, build trust and confidence, and promote dialogue between policy-makers, university research and training institution backed by appropriate, adequate and broad database should be put in place.
\end{abstract}

Keywords: Scientific Research; Policy-Making; Policy-Makers; University; Research Institutions, Interface; Africa

DOI: $10.7176 / \mathrm{PPAR} / 10-5-07$

Publication date:May $31^{\text {st }} 2020$

\section{Introduction}

The central argument of this paper is that it is the responsibility of university and research institutions; given the appropriate and conducive research environment, to undertake objective scientific research which can serve as the basis of formulating sound and sustainable socio-economic development policies in African countries (German Development Institute, 2018). This is because: (a) the pace of national development in many countries depends on the state of the knowledge of scientific research endeavours; and (b) the ability of policy-makers to translate the knowledge into specific-packages, programs and projects (CODESRIA, 1990; Jasanoff, 2004).

In order for scientific research results to have the desirable impact on the policy-making process and the socio-economic development of the continent, African social science, African Universities and Research institutions must address their research endeavours to the contemporary issues, challenges and problems of national development of African countries (Bujra and Khidir, 1992; CAFRAD, 1995).

To this extent, the purpose of this paper is three fold: First, to examine the status and challenges of scientific research in African countries; second to demonstrate the importance of scientific research as a foundation of sound government policy in Africa where economic and social indicators are generally inadequate, crude and unreliable; and third, to propose some guidelines for enhancing interface or dialogue between government policy-makers and University and research institutions and sustaining the process of promoting effective interface through national, regional and international research networks, between policy-makers and University and research institutions in Africa (Ake, 1980; Bujra and Khidir, 1992). The rest of the paper is structured as follows: section two looks at the status and challenges of scientific research; section three presents the vitality of scientific research in government policy-making; section four highlights some policy implications; and section five concludes the paper.

\section{The Status and Challenges of Scientific Research in African Countries}

Scientific research as a tool of government policy has not been given adequate attention by policy-makers in many African Countries as exemplified by the inadequate financial and material support for research institutions and the poor utilization of research results (Ake, 1980). Inadequate or no coordination between scientific research endeavours and government policies, which have often failed or performed poorly, e.g. the case of many State and Para-public bodies established to achieve the same objectives and goals (Nagel, 1992).

The tedious administrative red-tape under which many scientific research activities function has led to the frustration of many researchers, thereby making the later to be less interested in the research activities of their countries (Bujra and Mkandawire, 1980). In fact, the relationship between policy-makers and University/research 
and training institutions in many African countries, has not been very encouraging, particularly in those countries which have not established formal national structures for interface and dialogue (Bujra and Mkandawire, 1980; UNECA, 1992; CAFRAD, 1995). The dilemma in promoting interface include supply-driven consultancy research vs demand driven consultancy, maintaining appropriate balance between the use of local and foreign experts in policy-formulation, autonomy vs dependence in determining scientific research priorities, etc. (Odhiambo and Isoun, 1988, German Development Institute, 2018).

Impediments to interface from the perspective of research institutions include the general tardiness of the public service, lack of organized information, absence of transparency, tendency of politicians to use research results or findings for political ends, bureaucratic red-tapes and conservatism, poor remuneration of scientific research effort, discriminatory practices, obsession with foreign experts, etc. (Nagel, 1992; CODESRIA, 1990).

From the point of view of the policy-makers, there is lack of research capacity, existence of confidence and loyalty gap, and the general mistrust of African scientific researchers (Ndongko, 1985). It is therefore Important for both policy-makers and University research institutions in African countries to recognize the importance and relevance of scientific research as a tool of policy-making.

\section{Scientific Research as a Vital Tool of Government Policy-Making in African Countries}

3.1.1. Scientific Research has three distinct but interrelated phases of operation which are:

i. The investigation of the economic, political, cultural and social structures of the country in question, e.g. studies undertaken by the former Institute of Human Sciences of Cameroon on the socioeconomic impact of cooperative movements; demographic shift in Cameroon, notably on rural-urban migration of youths; disenclavement policies on the local population, etc. (Ndongko, 1992);

ii. The diagnosis or description of events taking place in the system and the analysis of factors which have accounted for such events; and

iii. The prediction of future trends and patterns of developments in the socio-economic system under study.

3.2. Government policy refers to the government efforts to look after "general interest"

either by (i) changing the qualitative aspects of the existing system (e.g. the creation of a Para-public cooperation) or (ii) changing within the quantitative framework of the given economic or social structure certain parameters which are termed instruments of policy (e.g. the personal income tax rate).

3.3. The objectives of government policy are to:

(i) Fix a collective or preference indicator (e.g. a national development plan which highlights the broad development goals);

(ii) Choose the relevant and adequate instruments of policy for the realisation of the national development goals; and

(iii) Establish the relationship between goals and policy-instruments on the one hand and the structure of the economy on the other.

3.4. Policy formulation, like scientific research, involves three closely related phases:

(i) Selection of the objectives or goals to be attained;

(ii) The choice of relevant policy instruments; and

(iii) The specification of the relationship between the stated goals, chosen policy instruments and the socio-economic structure.

3.5. Sound government policy requires objective scientific research on many counts:

(i) The establishment of a collective or preference function requires a complete knowledge of the socioeconomic behaviour of individuals and actors in the society as well as the development indicator of the system (Jasanoff, 1994);

(ii) The analysis of relevant data (on any aspect of the structure of the country) which reveals any changes in the system, enables policy-maker to identify those issues and problems which call for government action;

(iii) The specification of the relationship between the goals and instruments of socio-economic development policy requires an application of the knowledge of scientific research techniques (Jasanoff, 2004). This enables the policy-maker to determine the expected or potential impact of a selected policy instrument or a set of policy instruments on a particular policy goal or objective (Aiyepeku, 1982).

In view of the foregoing analysis, it is obvious that the success of any government policy requires continuous and effective collaboration between Universities and research institutions and decision-makers on national 
development issues (Diejomaoh, 1992; Choge et al., 2014). The effective utilization of scientific research as inputs into policy-making process will depend largely on the manner in which the research results are packaged, presented and understood by African policy-makers (UNECA, 1979 and 1992). The sad experience of the former Institute of Human Sciences of Cameroon where weak research methodology and analytical techniques, lack of appreciation of rigour of scientific research and the absence of effective communication between the policy-makers and researchers, led to limited research output vulgarisation, and impact on the socio-economic development of the country (Ndongko, 1992).

\section{Policy Implications}

In view of the importance of scientific research as a tool of policy-formulation in African countries, as well as the implementation and monitoring of government programs, the following recommendations are made in respect of (a) interface or dialogue between policy-makers and University, research / training institutions, and (b) sustaining the process of promoting more effective interface (Bujra and Khidir, 1992).

\subsection{On the Role and Responsibilities of African Governments, it is recommended that:}

First, governments should strive to provide formal institutional frameworks to support collaboration and cooperation between University and research institutions and policy makers (Diejomaoh, 1992);

Second, African countries should organize workshops and seminars at which University and research institutions and policy makers could interact and discuss policy issues, challenges and problems;

Third, the responsibility for establishing specific interface mechanisms should be the dual responsibility of African policy-makers and University and research and training institutions (German Development Institute, 2018);

Fourth, the interface between policy makers, University research and training institution should be backed by appropriate, adequate and broad database (German Development Institute, 2018);

Fifth, Various avenues for effecting contacts between policy-makers and University research institutions should be explored;

Sixth, in countries where many university and research institutions exist, an independent central co-ordinating organ should be established to monitor and collate scientific research findings, as well as to provide a forum for the discussion of problems and promote policy-making consensus;

Seventh, in order to promote and enhance national development by local consultancy capacity and pay local consultants reasonable and acceptable remunerations that they would not regard as discriminatory, African governments should establish clear guidelines for the fair compensation of national experts (German Development Institute, 2018);

Eighth, to ensure that university research institutions are involved and contribute effectively to the national development process, African governments should provide adequate funding and infrastructure for research;

To ensure the rationale and efficient utilization of existing indigenous skills and manpower resources, African governments should encourage the development of a data bank of national experts;

Ninth, African governments should keep university and research institutions informed of their policy and national development priorities.

Tenth, where African governments directly assume the role of appointing officials of University and research institutions, it is recommended that they make such appointments on the basis of merit;

Eleventh, African government should create institutional arrangements that would provide for regular interaction between policy-makers, University and research institutions.

Twelfth, African governments should recognise the fact that university, research and training institutions have important roles to play in the training of highly skilled manpower and in the improvement of management capacity;

Last, African governments are encouraged to develop policy analysis units in key sector ministries and departments. This will help to avoid piece-meal policies that have not been subjected to critical objective examination (Mohrir, 1992)

\subsection{On the Role and Responsibilities of Universities and Research Institutions in the enhancement of dialogue and Interface, it is recommended as follows:}

First, liaison offices, staffed with competent officers, be established by the universities and research institutions. These offices should be designed to act as liaison channels with policy-making centres. Through these arrangements, universities and research institutions could inform the policy centres of their on-going research and the findings of their completed research, together with annotated synopsis of their policy implications (German Development Institute, 2018).

Second, research institutions and universities should aim at excellence by improving upon the quality of their scientific research. This calls for a rigorous internal self-assessment in the areas of research designing, methodology, data collection, report writing and report packaging. The credibility and therefore, continuous acceptance of the relevance of these institutions to a large extent depend on the quality of the outputs they deliver 
(UNECA, 1992).

Third, to win the confidence and trust of policy-makers, universities and research institutions should establish sound internal management and administrative procedures and guideline. Their financial administration and other management systems should be transparent (German Development Institute, 2018).

Forth, universities and research institutions must be proactive in outlook by keeping pace with the thinking of African governments on national development issues and problems.

\subsection{Towards Enhancing Interface Between Policy-Makers, Research and Training Institutions}

In order for the proposed collaboration and interface, sections A and B to be enduring and self-sustaining, definite strategies will have to be marshalled, deployed, monitored and constantly evaluated to guarantee their effectiveness. In this regard, there must be the adoption of a regional scientific research policy at the level of the continent with the establishment of national implementation strategies. This should be accompanied by the creation of national and international networks with adequate technical and infrastructural support. An important requirement thereafter should be the adoption of action plans which emphasize national development priorities with the view to orienting research towards the satisfaction of socio-economic development and political needs (Maliyam, 1992).

Human resource development and effective utilisation by both policy-makers and university and research utilisation constitute an essential component of the package of policy measures required to sustain a durable interface (Bujra and Khidir, 1992). There is no doubt that the presence of a crop of professionally qualified and practically experienced staff of both sides could enhance the efforts towards meaningful dialogue and collaboration (Knott and Aron, 1980). Specific steps should therefore be taken to make appropriate regular and systematic training available to university, research institution and policy-makers (Mkandawire, 1989).

As the interface between policy-makers and university, research and training institutions can best thrive in an environment characterized by peace, stability, transparency, tolerance of ideas and one that has established mechanisms for resolving policy differences, public policy-making should be approached as an open system which can accommodate various the view points of the different actors in the system (Ndongko, 1992; Hayes, 2001). To ensure sustained dialogue between the two actors, efforts should be made to remove legal and other restrictive regulations and obstacles that may hinder effective interface. A sustained and effective interface can be achieved only in circumstances where the capacity for such an interface exists on both sides (Mkandawire, 1989).

To improve and enhance the capacity for interaction, it is important at the initial stage to take an inventory of what exist. To this effect, it is recommended that directories of officials of university and research institutions, funding agencies, publishing houses, professional associations be compiled in order to sustain, constantly upgrade and strengthen existing capacity to resolve policy issues and problems and to avail decision makers of the information needed for effective policy-making (Ndongko, 1985; Aiyepeku, 1980; Choge et al., 2014).

Additionally, it is recommended that some modalities for sustained interface and promotion of dialogue between the government policy-makers and University research and training institutions be spelt out. These modalities are that: a national forum be created for dialogue between prominent policy makers and university and research institutions; universities, research and training institutions should give more visibility to their scientific research activities; African governments should make increased use of indigenous consultants/researchers for the analysis and evaluation of policy issues; African governments should encourage access to policy data by universities and research institutions (Choge et al., 2014); and special seminars and workshops should be conducted for serving policy-makers on policy analysis and policy-making issues (Mohrir, 1992).

\section{Conclusion}

Since African governments can benefit from the detached objectivity and familiarity with scientific process and evaluation methodology, it is recommended that they involve academics and researchers in the monitoring and evaluation of public policies. It is also strongly recommended that all policy analysis activities be institutionalized. To this extent, a catalytic group conversant with policy analysis/policy methodology and close to the organizational leadership be constituted to provide a forum for meaningful dialogue between academics/researchers and policymakers (Maliyam, 1992). Furthermore, a mechanism for the enrichment of experience be provided so as to enable researchers and academics to work in policy-making roles and practitioners to spend some time in research institutions reflecting on their experience and interacting with researchers (Diejomaoh, 1992).

In view of the usefulness of disseminating knowledge and information on policy issues and other issues relevant to the interface, it is recommended that books, journals, special bulletins and research reports of importance to policy makers be published and widely disseminated (Aiyepeku, 1978; Knott and Aron, 1980). Efforts should be made to mobilize funding from donors, the private sector and other sources. Attempts should be made to supplement the shrinking research funding caused by the economic crisis being experienced by many African countries.

It should be pointed out that in spite of the shrinking funding base, it is still possible to generate additional resources provided it can be shown that the research activities would be useful to the State, the private sector or 
the society at large. Viable and well-focused research programs, properly packaged and presented could stand a good chance of funding (Maliyam, 1992).

While it is recognized that many activities which are aimed at enhancing interface may not require additional funding as most of the basic infrastructure may already be in place. Nevertheless, it is recommended that additional resources be tapped from the actors in the interface process. To this extent, it is recommended that national focal points be established to initiate action and also act as catalysts and monitoring units in the sustaining process.

Finally, the United Nations Economic Commission for Africa (UNECA) is urged to initiate action at the regional level by approaching African Governments, through its established research channels, to institutionalize measures aimed at sustainable policy interface. In this regard, it is recommended that UNECA should organize regional seminars aimed at getting the above initiatives underway. The seminars could then be used to launch national focal points constituted from senior government policy-makers and researchers from universities and research institutions. Finally, UNECA should indicate its willingness to assist those African countries interested in participating in this important initiative.

As a concluding note to this paper, there is no doubt that the effective utilisation of Africa's human resources can play a major role in stimulating its economies and putting the continent back to recovery and sustained economic growth and development. This is extremely important because Africa`s track record of tapping existing resources in the Universities and Research institutions for policy development (analysis, formulation, implementation and evaluation) has not been very encouraging and leaves much to be desired (Choge et al., 2014).

\section{References}

Aiyepeku, W, O. (1978). Organizational Considerations in the Information / Utilization Mode of African Policymakers, in c.o. Kisiedu (ed) Intormation for Economic Planning and Development for the African Region, Legon.

Aiyepeku, W, O. (1980). The Perception and Utilization of Information by Policy-Makers in Nigeria, Lagos, National Library of Nigeria.

Aiyepeku, W, O. (1982), The Perceived Responsibilities of NISER in the Dissemination of Development Information. Nigerian Journal of Economic and Social Studies. Vol. 24, No. 1.

Ake, C. (1980). Social Sciences and Development. Africa Development CODESRIA. Vol. 5, No. 4, Dakar.

Choge, I., Otieno, O., Erasmus, Y., Zaranyika, H., Langer, L., and Stewart, R. (2014). An

Overview of Role Players Facilitating Evidence-Informed Decision-Making in South Africa. A Landscape Review. Retrieved from http://www.africaevidencenetwork.org/wp content/uploads/2014/08/Landscape-Review-ofRoleplayers- in-Evidence-Use-in-South-Africa.pdf.

Bujra, A., and Mkandawire, T. (1980). The Evaluation of Social Science in Africa: Problems and Prospects. Africa Development. Vol. 4, No. 4, Dakar.

Bujra, A, S., and Khidir, E, E. (1992). Dialogue Between Policy-Makers and Research Institutions: The Historical and Socio-Political Context. Paper presented at the ECA/PHSD/SAPAM, Senior Policy Workshop, Rabat.

CAFRAD (1995). Implications des institutions de Formation et de Recherche dans le Processus des Reformes et du Développement en Afrique : Exemple et Rôle de CAFRAD. Paper presented at the ECA/PHSD/SAPAM Senior Policy Workshop, Rabat.

CODESRIA (1990). The State and Social Sciences. Proceedings of the Sixth General Assembly of CODESRIA, Dakar.

Diejomaoh, V. P. (1992). Social Science Priorities for National Development. Research for Development. Vol. 2 , No. 2.

German Development Institute (2018). The Interface between Research and Policy-Making in South Africa: Exploring the Institutional Framework and Practice of an Uneasy Relationship. Discussion Paper. No. $19 / 2018$.

Hayes, W. (2001). The public policy cycle. School of Social Science and Human Service, Ramapo College, NJ. Retrieved from http://profwork.org/pp/intro/cycle.html.

Jasanoff, S. (1994). The fifth branch. Science advisers as policymakers. Cambridge, Mass: Harvard University Press.

Jasanoff, S. (Ed.). (2004). States of knowledge. The co-production of science. London: Routledge.

Knott, J., and Aron, W. (1980). If Dissemination is the Solution, what is the Problem. Knowledge Creation, Diffusion, Utilisation. Vol. 1 No. 4.

Maliyam, K, T. H. (1992). The Contribution of Policy-Oriented Research Centres to Economic Reform and Development: Problems and Possibilities. Paper presented at the ECA/PHSD/SAPAM Senior Policy Workshop, Rabat.

Mkandawire, T. (1989). Introductory Remarks on the African Social Science Research Environment. APPA Newletter, Lagos.

Mohrir, V. N. (1992). Institutionalisation of Policy Analysis in Developing Countries: An Explanatory Approach. 
Paper Presented at ECA/PHSD/SAPAM, Senior Policy Workshop, Rabat.

Nagel, S, S. (1992). The Need for Improved Policy Analysis in Developing and Industrialized Nations. Paper presented at the ECA/PHSD/SAPAM Senior Policy Workshop, Rabat.

Ndongko, W.A. (1985). The Utilisation of Social Sciences in the Formulation of Policy: The Cameroon Experience. CODESRIA Conference on the Utilisation of Social Sciences in Policy Formulation and Research in African Universities, Dakar.

Ndongko, W. A. (1985). Reflections on The Economic Policies and Development of Cameroon. MESRES/ISH, Yaounde.

Ndongko, W.A. (1992). Social Science Research and Policy-Making in Developing Countries: A Critical Analysis. Paper present at ECA/PHSD/SAPAM/ Senior Policy Workshop, Rabat.

Odhiambo, T. R., and Isoun, 1. (1988) eds. Science for Development in Africa. Academy of Science Publishers, Nairobi.

UNECA (1979). DEVSIS8 Africa: A Pan African Documentation and Information System for Social and Economic Development. Assis Ababa.

UNECA (1992). Synthesis of Selected Country Experiences. Paper presented at the ECA/PHSD/SAPAM Senior Policy Workshop, Rabat.

UNECA (1992). Notes on the Guidelines for Promoting More Effective Interface Between Policy-makers and Training/Research Institutions. Paper presented at the ECA/PHSD/SAPAM Senior Policy Workshop, Rabat. 